\title{
RET Oncoprotein
}

National Cancer Institute

\section{Source}

National Cancer Institute. RET Oncoprotein. NCI Thesaurus. Code C19954.

Human RET Oncoprotein is a product of mutated variants (Oncogene RET) of RET Gene, which encodes Tyrosine-Protein Kinase Receptor RET, a type I membrane protein receptor for Glial Cell Line-Derived with an extracellular cadherin-like domain and important in neural crest development. Some oncogenic RET point mutations cause constitutive kinase activation. PTC1 oncogene involves fusion of RET kinase to the H4 dimerization leucine zipper. In PT C6, RET is fused to the N-terminal part of Transcriptional Intermediary Factor-1-Alpha. In PT C7, RET is fused to a C-terminal part of TIF1-Gamma. Oncogenic RET mutations are associated with Hirschsprung's disease, Multiple Endocrine Neoplasia, pheochromocytoma, hyperparathyroidism and medullary thyroid cancer. RET Oncoprotein disrupts normal cell function. 